\title{
A GEOGRAFIA ESCOLAR E O CONCEITO DE PAISAGEM
}

\author{
Marley Trajano Lima ${ }^{\text {(a) }}$ Tamara Foscarim Moreira ${ }^{\text {(b) }}$ Abraão Levi dos Santos Mascarenhas (c) \\ Maria Rita Vidal ${ }^{(d)}$ \\ (a)Faculdade de Geografia- Universidade do Sul e Sudeste do Pará, marleytl@ live.com \\ (b) Faculdade de Geografia- Universidade do Sul e Sudeste do Pará, tamara.foscarim@outlook.com \\ (c)Faculdade de Geografia- Universidade do Sul e Sudeste do Pará, abraaolevi@unifesspa.edu.br \\ ${ }^{(d)}$ Faculdade de Geografia- Universidade do Sul e Sudeste do Pará, ritavidal@unifesspa.edu.br
}

EIXO: GEOGRAFIA FÍSICA - CURRÍCULO, FORMAÇÃO E PRATICAS DE ENSINO.

\section{Resumo}

O presente trabalho objetiva discutir as transformações no espaço geográfico de Marabá em sala de aula, através da utilização de fotografias atuais e imagens antigas da paisagem. As imagens permitem trabalhar em com os alunos as mudanças que se dão na paisagem urbana. $\mathrm{O}$ foco do trabalho está direcionamento para estudantes do ensino básico. Como resultado encontrado observou-se que o uso das fotografias vem como uma proposta de dinamização das aulas de geografia, saindo dos modelos tradicionais. Portanto, a imagem se mostra como proposta metodológica válida no ensino de geografia a sua função fundamental se expressa por facilitar o conhecimento, tornando-os em alguns momentos mais didático e em outros mais lúdico, o que gera maior interesse aos discentes.

Palavras chaves: Fotografias; paisagem; ensino de geografia; tempo, espaço.

\section{Introdução}

O conceito de paisagem está premente entre docentes e discentes na área da ciência geográfica, conceito este que sofre variações entre as diferentes escolas de estudos das paisagens. O que seria paisagem? Ela é tudo aquilo que a vista pode alcançar? Segundo Besse (2006, p.69), "mesmo que a paisagem possua uma dimensão visível, seu conteúdo não se limita aquilo que se pode ver". Assim, paisagem é tudo que vai além do que podemos enxergar, ela é um conjunto inter-relacionado de formações naturais e antroponaturais (Rodriguez, Silva e Cavalcanti, 2004). O elemento cidade é uma das vertentes que o conceito de paisagem pode abordar. Ao longo do tempo a paisagem sofre transformações, sendo modificada tanto por ações do antrópicas como por ações da própria natureza levando a paisagem a modificações, desencandeando um processo de dinâmicas ou evoluções do meio. De acordo com Moreira (2016, p.15), as transformações ocorridas no espaço geográfico de Marabá a partir da década de 1970 alteraram a paisagem natural e urbana, trazendo mudanças significativas nessa paisagem. As mudanças impostas as paisagens, através dos aspectos naturais ou antrópicos como (erosão, degradação do solo, desmatamento, construções, ação pluvial e fluvial, etc.) são expressas por processos dinâmicos. Com base nisso, pode-se compreender e interpretar os problemas ambientais e elaborar proposições que subsidiem o ordenamento territorial das cidades. As imagens ou fotografias se mostram como uma ferramenta didática para o ensino como forma de 
XVII Simpósio Brasileiro

de Geografia Fisica Aplicada

I Congresso Nacional

de Geografia Física
OS DESAFIOS DA GEOGRAFIA FÍSICA NA FRONTEIRA DO CONHECIMENTO

Instituto de Geociências - Unicamp

Campinas - SP

28 de Junho à 02 de Julho de 2017

trabalhar nas escolas as mudanças ocorridas na cidade em processos históricos distintos. Dessa forma, o objetivo do presente trabalho se pontua em discutir as transformações no espaço geográfico de Marabá em sala de aula, através da utilização de fotografias atuais e imagens antigas. Sendo esta de significativa importância como aborda Moreira (2016, p. 16), "no ensino de Geografia a utilização de imagem é primordial para a explicação e entendimento dos fenômenos ligados a todo tipo de natureza". No entanto, sabe-se que estas possuem um papel secundário, que em boa parte das atividades em sala é tida como mera ilustração. Sobre a importância da utilização de imagens como recurso, está pontuada nos Parâmetros Curriculares Nacionais (2001, p. 118), onde indicam que "o ensino de geografia deve se utilizar de imagens e recorrer a diferentes linguagens na busca de práticas que levem a uma nova forma de expressar suas interpretações, hipóteses e conceitos".

\section{Metodologia}

A pesquisa encontra-se em estágio preliminar, fazendo parte das atividades do Pibid, desenvolvida através do Grupo de Pesquisa do CNPq intitulado: Geoecologia das Paisagens e Sistemas Geoinformativos do Curso de Geografia da Unifesspa. Buscando abarcar o máximo de contribuições ao ensino de Geografia das Paisagens, o estudo segue as proposições de Cavalcanti (2008), no tocante a aplicação da cidade como instrumento pedagógico, logo que, esse recurso servirá para aprendizagem cognitiva e compreensão do tempo/espaço onde habitam os alunos. A proposta inicial segue com a revisão bibliográfica e uma análise das obras acerca da temática discutida, que podem incluir as atividades com imagens no seu bojo, tendo como fonte autores: Vidal (2014); Cavalcanti (1988); Castrovianni (2002); Callai (1999), ambos são utilizados, por trazerem contribuições relevantes e proporcionarem uma dimensão ampliada dos saberes geográficos aqui estudados. Posteriormente, farse-á uso da observação direta da prática docente com imagens em sala de aula, com intuito de compreender o processo de ensino aprendizagem das transformações no espaço urbano e sua relação com as transformações da paisagem. A utilização de imagens tem como objetivo nortear os estudantes, para que os mesmos possam adquirir ou identificar as paisagens atuais e antigas (fotografias), na qual poderá ser construído um condicionante das paisagens na cidade.

\section{Resultados e Discussão}

\subsection{As mudanças nas paisagens de marabá tempo/espaço}

A utilização de fotografias como recurso didático é indispensável em várias áreas da ciência, em especial para a Geografia, que pode ajudar desenvolver no aluno a capacidade de analisar o espaço geográfico de uma forma diferenciada, pois dá a este aluno a oportunidade de visualizar aquilo que imaginou. Dessa forma, o aluno apreende um conhecimento mais apurado, podendo assim desenvolver a sua capacidade crítica e interpretativa, através das imagens que expressam as paisagens. As 
XVII Simpósio Brasileiro de Geografia Fisica Aplicada

I Congresso Nacional de Geografia Física

\section{OS DESAFIOS DA GEOGRAFIA FÍSICA NA FRONTEIRA DO CONHECIMENTO \\ Instituto de Geociências - Unicamp Campinas - SP \\ 28 de Junho à 02 de Julho de 2017}

categorias como território e paisagem, são imprescindíveis para a análise da cidade e as modificações da paisagem.

De acordo com Cavalcanti (2008, p. 51).

[...] a paisagem o domínio do visível - a expressão visível de um espaço -, o domínio do aparente, de tudo o que nossa visão alcança; o domínio do queé vivido diretamente com nosso corpo, com nossos sentidos - visão, audição, tato, olfato, paladar; ou seja, trata-se da dimensão das formas que expressam o movimento da sociedade. A observação e a compreensão dessas formas servem para dar caminhos de análises do espaço.

Assim, as mudanças na paisagem são algo inevitável em qualquer espaço geográfico, pois o meio vem se modificando até os dias atuais. Mas, como aborda Castrogiovanni $(2002$, p.110) "A paisagem é tudo aquilo que se vê, e a nossa visão depende da localização em que se está. Daí decorre que ela pode ser observada de escalas diferentes [...]." O tipo de olhar é o determinante da forma de demonstração da paisagem, e isso vai depender do olhar diferenciado que cada um lança sobre ela. No tocante a cidade, Cavalcanti (2008, p. 55) lembra que "a compreensão do tema cidade pelos alunos exige tratamento interdisciplinar, requer a formação de um sistema amplo de conceitos, a aquisição de muita informação e o desenvolvimento de uma série de capacidades e habilidades", o que confere complexidade frente às degradações/impactos que se apresentam das relações entre paisagem e o espaço urbano. Segundo Vidal (2014, p.32) “O homem acelera a degradação e destruição dos ambientes naturais". Os tempos contemporâneos o homem (antropológico) emprega significativas modificações na paisagem. Segundo Rodriguez, Silva e Cavalcante (2004, p.15), “o homem não modifica as leis da natureza, mas transforma de maneira significativa as condições de suas manifestação”. Seguindo essa linha de raciocínio, Marabá é uma cidade margeada de rios (Itacaúnas e Tocantins), e se torna fato, que as ações da hidrografia e pluviosidade prevalecem nessa paisagem (Figura 1).
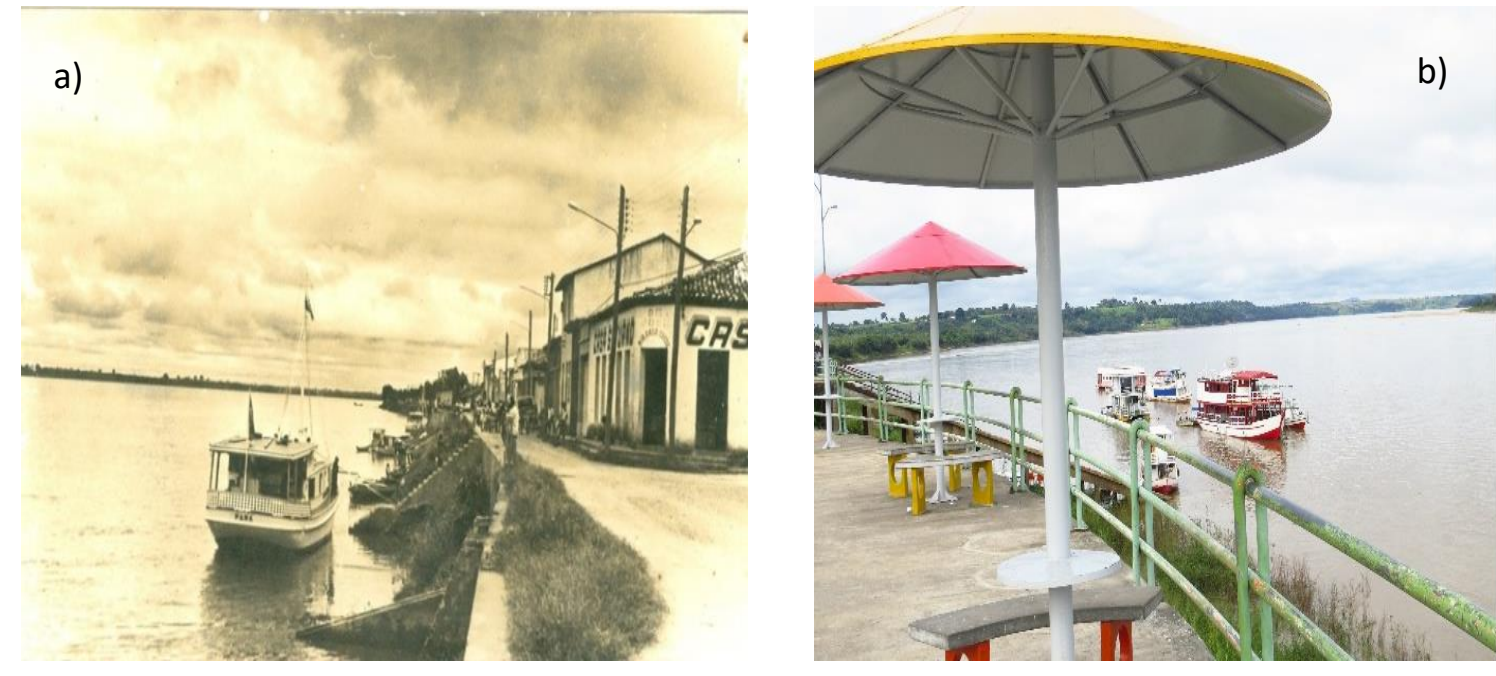

Figu ra 1Asp ecto $\mathrm{s}$ gera is da orla na cida de form as 
XVII Simpósio Brasileiro

de Geografia Fisica Aplicada

I Congresso Nacional

de Geografia Física
OS DESAFIOS DA GEOGRAFIA FISICA NA FRONTEIRA DO CONHECIMENTO

Instituto de Geociências - Unicamp

Campinas - SP

28 de Junho à 02 de Julho de 2017

de locomoção a), orla (cais) de Marabá em 1971. Em b) visão atual da orla de Marabá (2017). Fonte: Fundação

Casa da Cultura de Marabá e Lima (2017), respectivamente.

A imagem da Figura 1, apresenta o arcabouço histórico, apontando as formas de locomoção no espaço da cidade, onde utilizava sobretudo as canoas e barcos de madeiras para tal finalidade. Esses tipos de embarcações prevalecem nos dias atuais, porém com mudanças na finalidade, por motivos tantos da estrutura natural (dinâmica dos rios) como econômicos direcionado ao turismo na região. Outro fator que se expressa é o aspecto físico dessa paisagem modificada principalmente por meios antropológicos. E é justamente esse processo de modificação espacial de tempo/espaço que deve ser analisada e compreendida pelo estudante, para que ele possa melhorar sua capacidade cognitiva em relação a morfologia de uma dada paisagem. O desenvolvimento da urbanização na cidade de Marabá, cria-se a necessidade da construção de elos de ligação (pontes), entre os diversos núcleos da cidade, tem-se então, a inserção das estradas que está diretamente ligada a construção da ponte sobre o rio Tocantins, mudando totalmente a paisagem desse espaço (Figura 2).
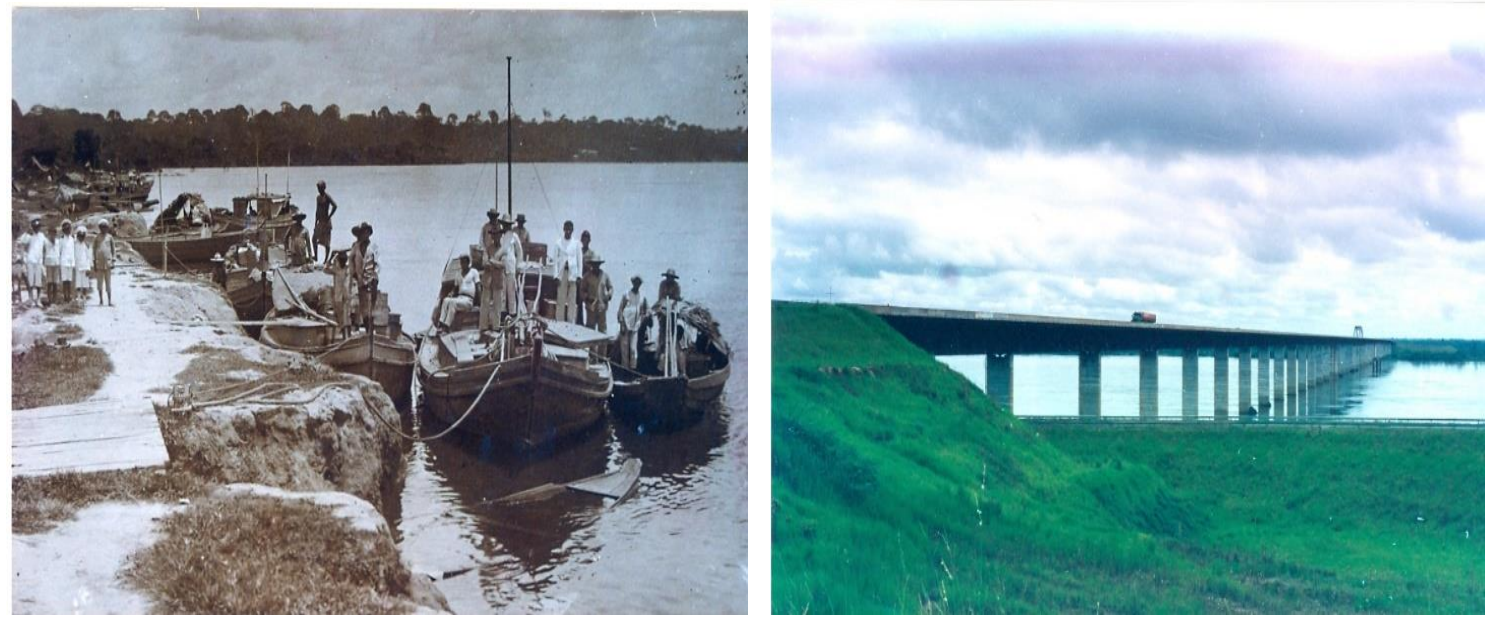

Figura 2- O transporte pelas águas: Em a) Cais do Rio Tocantins na década de 1970. Em b) Ponte sobre o Rio Tocantins construída na década de 1980. Fonte: Fundação Casa da Cultura de Marabá.

Nas imagens da figura 2, percebe-se como o homem modifica o espaço geográfico, alterando aspectos físicos e visuais na paisagem, essas modificações se dão de acordo com suas necessidades vigentes, essas modificações vão de acordo com as colocações de Vidal (2014, p.16), "as relações entre a sociedade e natureza estão intimamente ligadas às necessidades de produção". Com isso ouve a transformação dessa paisagem para que existisse de forma mais rápida e prática a locomoção de pessoas e materiais na cidade. Podemos verificar assim, que onde prevaleciam os barcos como principal meio de locomoção, atualmente a hegemonia dos veículos - que através de pontes sobre os rios dão a tônica a essa paisagem.

\section{Conclusão}


As significativas mudanças na paisagem da cidade de marabá ao longo de quase 50 anos (1971 à 2017), expressam ações de dinâmicas e evoluções, pontuados por construções de pontes, rodovias, ferrovias que levaram a estruturação da cidade e também a degradação de áreas significativas dessa paisagem. Verifica-se também que o homem muda a paisagem como elemento de força exógena, ao mesmo tempo ele é paisagem no aspecto natural, modificando o seu próprio meio de convívio no espaço. A partir do estudo da paisagem, é possível vivenciar um primeiro plano de percepção das mudanças na paisagem, além possibilitar aos alunos criar elos afetivos e sentir-se parte integrante dessa paisagem. Essa construção de significados acontece a partir das relações estabelecidas entre o que se observa e o que se vivencia. As fotografias/imagens que retratam as paisagens da cidade se mostram como um recurso didático eficaz no ensino de geografia física, facilitando a compreensão do estudante, sobre a interação de cada elemento composto e de forma hierárquica existente na paisagem levando os alunos a operar transformações no espaço vivido, porque estão se sentido parte integrante dele.

\section{REFERÊNCIAS}

BESSE, Ver a terra: seis ensaios sobre a paisagem e a geografia jean-marc BESSE São Paulo: Perspectiva, 2006.

CALLAI, H. C. A geografia no ensino médio. Terra Livre, n. 14. São Paulo, jan-jul. 1999.

CASTROGIOVANNI, A. C. (Org) Ensino de geografia: práticas e textualizações no cotidiano. Porto Alegre: Medição, 2000.

CAVALCANTI, Lana de Souza. Geografia, escola e construção de conhecimentos. Campinas: Papirus(1998).

CAVALCANTI, Lana de Souza, A geografia e a cidade: Ensaios sobre o ensino de geografia para a vida urbana cotidiana. Campinas, SP: Papirus, 2008.

MOREIRA, Elvis Vieira. Fotografia, paisagem e ensino de Geografia: proposta metodológica utilizando fotografia a partir do $8^{\circ}$ ano junto a escola Jonatas Athias. (Monografia). 2010. Universidade do sul e Sudeste do Pará.

RODRIGUEZ, José Manoel Mateo, SILVA, Edson Vicente, CAVALCANTI, Agostinho Paula.Geoecologia das paisagens: uma visão geosistemica da análise ambiental.2. ed. Fortaleza: Edições UFC, 2007.

SCHNELL, Rogério. O uso da fotografia em sala de aula palmeira: espaço urbano, econômico e sociabilidades, a fotografia como fonte para a história. PUC/PR, 2004.

SOTCHAVA, V. B. O estudo de geossistemas. Métodos em Questão, São Paulo, n. 16, 1977. 
VIDAL, Maria Rita. Geoecologia das paisagens: Fundamentos e aplicabilidades para o planejamento ambiental no baixo curso do rio curu-ceará-brasil, 2014. 204 p. Tese (Doutorado em Geografia). Universidade Federal do Ceara. Fortaleza-CE, 2014. 